\title{
Transtorno de Déficit de Atenção com Hiperatividade: classificação e classificados ${ }^{1}$
}

| ${ }^{1}$ Fabíola Stolf Brzozowski, ${ }^{2}$ Sandra Caponi |

Resumo: O objetivo principal deste artigo foi analisar a visão de pais e professores sobre o diagnóstico do Transtorno de Déficit de Atenção com Hiperatividade (TDAH) e seu efeito sobre as crianças com esse problema. Para tal objetivo, foram entrevistados mães e professores de crianças diagnosticadas com TDAH, através de um roteiro de pesquisa semiestruturado. $\mathrm{O}$ artigo analisará um eixo temático que surgiu a partir da pesquisa, chamado de classificação e classificados. A estrutura de uma classificação, para Ian Hacking, engloba cinco aspectos principais:

a classificação em si, os indivíduos classificados, as instituições, o conhecimento e os especialistas. Esse autor afirma que toda classificação de pessoas gera uma resposta, ou seja, classificação e indivíduo interagem, formando um ciclo, que ele chamou de efeito de arco. O TDAH é um diagnóstico médico e, portanto, uma classificação. Os indivíduos classificados são as crianças com diagnóstico de TDAH. Mesmo que a criança seja pequena e não entenda o significado da classificação que lhe foi dada, pretende-se mostrar que mesmo assim é possível que ocorra o efeito de arco. A criança, por meio das modificações sofridas no meio social no qual ela vive, se modifica. As instituições são responsáveis pela legitimação do diagnóstico e, no caso do TDAH, são os locais onde se encontram os profissionais da saúde e a escola. Além disso, por trás de uma classificação existe um corpo de conhecimento sobre ela e parte desse conhecimento, geralmente o "oficial", é dominado pelos especialistas da área, que os repassam aos demais.

> Palavras-chave: Classificação de pessoas; TDAH; efeito de arco.

\footnotetext{
1 Aluna do Programa de PósGraduação em Saúde Pública, Departamento de Saúde Pública, Universidade Federal de Santa Catarina, Florianópolis-SC. Endereço eletrônico: fabijerzy@ yahoo.com

2 Professora do Programa de Pós-Graduação em Saúde Pública, Departamento de Saúde Pública, Universidade Federal de Santa Catarina, Florianópolis-SC
} 
O filósofo da ciência Ian Hacking (HACKING, 2006) diz que nosso mundo é um mundo de classificações e que essas classificações, ou nomes, têm efeitos particulares quando se referem a comportamentos de pessoas. Escreve também que, por trás de cada classificação, existe uma estrutura que engloba cinco aspectos primários: a classificação, os indivíduos, as instituições, o conhecimento e os especialistas.

A classificação em si gera os tipos de pessoas, e é formada por individuos que compartilham o mesmo problema. Esse grupo de pessoas possui um nome e suas características são determinadas em função desse nome. As instituiçôes confirmam a existência dessa classificação e são um meio de legitimar aquele tipo de pessoas. E é através do conhecimento que se pode decidir quem é doente e quem não é. São os especialistas, por sua vez, que detêm o conhecimento e, portanto, são eles que primeiramente classificam (HACKING, 2007).

O Transtorno de Déficit de Atenção com Hiperatividade, doravante chamado de TDAH, é considerado o diagnóstico psiquiátrico mais comum na infância e se caracteriza por três categorias principais de sintomas, que são desatenção, impulsividade e hiperatividade (VASCONCELOS et al., 2003). No Brasil, a taxa de prevalência média encontrada nos estudos desse tipo foi de 3,6 a 5\% da população escolar (ANDRADE; SCHEUER, 2004), porém alguns estudos indicam uma taxa de até $12 \%$ dessa população (VASCONCELOS et al., 2003). O diagnóstico do TDAH se baseia em critérios estabelecidos em guidelines oficiais, e é essencialmente clínico e subjetivo.

Este artigo tem como objetivo analisar a visão de pais e professores sobre o diagnóstico do TDAH e seu efeito sobre as crianças com esse problema. Para tanto, está dividido em quatro seções principais. A primeira trata da classificação, ou seja, sobre o diagnóstico, como pais e professores o veem e por que ele existe. A seção seguinte é sobre os indivíduos, quer dizer, sobre as crianças classificadas com o diagnóstico do TDAH e como se dá sua relação com a escola e com a família, pela visão das mães e professores. $\mathrm{Na}$ terceira seção é abordado o tema da instituição, no caso, a escola, e como ela lida com os diagnósticos. A última seção discute o conhecimento e os especialistas, e nela é analisada a questão de como o profissional de saúde tem um papel fundamental na classificação e no efeito de $\operatorname{arco}^{2}$. 
O universo de estudo da pesquisa foram as mães e os professores de crianças com diagnóstico de TDAH. A intenção era descobrir o que eles pensam sobre a trajetória terapêutica dessas crianças, desde o descobrimento do problema, passando pelo diagnóstico, até chegar ao tratamento. Foram entrevistadas quatro mães e cinco profissionais da área de educação, pedagogos, que tinham ligação com as crianças em questão.

O local escolhido para a seleção dos participantes da pesquisa foi um município da região do Vale do Itajaí de Santa Catarina, com uma população aproximada de 35.000 habitantes. O município foi escolhido por ser de fácil acesso, uma vez que o pesquisador já tinha contatos com a Secretaria Municipal da Educação. Esse município conta com 16 escolas de ensino fundamental, sendo seis municipais, sete estaduais e três particulares.

As mães entrevistadas possuem de 28 a 45 anos e a maioria é do lar e não cursou todo o ensino fundamental. Seus filhos têm entre 7 e 14 anos; dois deles possuem o diagnóstico há três anos. Já a idade dos professores variou entre $37 \mathrm{e}$ 49 anos e todos possuem mais de 19 anos de experiência lidando com crianças. Essas mães e professores foram identificados por meio da Secretaria Municipal da Educação. A Secretária Municipal da Educação foi contatada, foram explicados a ela os objetivos da pesquisa, sua metodologia, ou seja, o projeto como um todo.

A coleta de dados foi realizada por meio de entrevistas em profundidade semiestruturadas, ou seja, partindo de um roteiro-base. $\mathrm{O}$ instrumento de coleta utilizado foi o gravador, que possibilitou o registro literal e integral da entrevista, oferecendo maior segurança à fonte. As informações obtidas foram classificadas de forma a estabelecer e organizar grupos de temas comuns, as categorias, que foram analisadas separadamente.

Para a elaboração dessas categorias e de seus subitens, foi utilizado como referencial teórico Laurence Bardin (BARDIN, 1977). Esse autor divide a análise de conteúdo em três fases: a pré-análise, a exploração do material e o tratamento dos resultados. As categorias foram pré-definidas, baseadas na classificação do autor utilizado como referencial teórico da análise, Ian Hacking. Na pré-análise foram selecionadas as partes das entrevistas que constituíram o que ele chama de corpus de análise. A fase de exploração do material serviu para separar o 
material e encontrar partes do corpus de análise para cada categoria definida. Por fim, a fase do tratamento dos resultados obtidos, que também não foi realizada isoladamente das demais, visou a tornar os dados válidos e significativos, por meio de uma análise teórica. Para isso, o material coletado foi confrontado com o material bibliográfico já previamente selecionado e outros relacionados a assuntos que surgiram a partir das fases de pré-análise e análise, tornando possível novas reflexōes sobre o tema abordado.

O eixo temático principal de análise do artigo foi chamado de classificação e classificados, que foi subdividido em subeixos para uma análise mais aprofundada de cada um: (a) a classificação; (b) os individuos, que, por ter sido um tema bastante citado, desse sub-eixo derivou mais um, chamado os informados; (c) as instituiçôes; (d) o conhecimento e os especialistas. O referencial teórico de análise desse eixo foi o autor Ian Hacking.

\section{A classificação}

O TDAH já foi conhecido por vários nomes durante o século XX, dentre eles "encefalite letárgica”, "dano cerebral mínimo", "disfunção cerebral mínima”, "hipercinesia", "doença do déficit de atenção" (DDA) e "transtorno de déficit de atenção com hiperatividade" (TIMIMI, 2002). Essas categorias de doença apresentam conjuntos de sintomas similares, que descrevem algumas características consideradas desvios da infância. Alguns dos sintomas mais comuns a todos esses nomes são: baixo desempenho na escola, extroversão extrema, comportamentos violentos, incapacidade de completar tarefas, ladroagem, distúrbios nos padrões de sono, moralidade inconsistente com a idade e esquecimento (RAFALOVICH, 2001a).

O nome Transtorno de Déficit de Atenção (TDA) surgiu pela primeira vez em 1980, no DSM-III ${ }^{3}$, que dividia a doença em dois tipos: TDA com hiperatividade e TDA sem hiperatividade. Na quarta edição do DSM (DSMIV), o nome passou a ser Transtorno de Déficit de Atenção com Hiperatividade (TDAH) (PHELAN, 2005). Os critérios diagnósticos utilizados atualmente são os que constam na revisão da quarta edição do DSM (DSM-IV-TR, 2002) e estão resumidos no quadro a seguir. 
Critérios Diagnósticos para Transtorno de Déficit de Atenção/Hiperatividade

A. $\mathrm{Ou}(1)$ ou (2)

seis (ou mais) dos seguintes sintomas de desatenção persistiram por pelo menos seis meses, em grau mal-adaptativo e inconsistente com o nivel de desenvolvimento:

Desatenção:

(a) frequentemente deixa de prestar atenção a detalhes ou comete erros por descuido em atividades escolares, de trabalho ou outras;

(b) com frequência tem dificuldades para manter a atenção em tarefas ou atividades lúdicas;

(c) com frequência parece não escutar quando lhe dirigem a palavra;

(d) com frequência não segue instruções e não termina seus deveres escolares, tarefas domésticas ou deveres profissionais (não devido a comportamento de oposição ou incapacidade de compreender instruções);

(e) com frequência tem dificuldade para organizar tarefas e atividades;

(f) com frequência evita, antipatiza ou reluta a envolver-se em tarefas que exijam esforço mental constante (como tarefas escolares ou deveres de casa);

(g) com frequência perde coisas necessárias para tarefas ou atividades (por ex., brinquedos, tarefas escolares, lápis, livros ou outros materiais);

(h) é facilmente distraído por estímulos alheios à tarefa;

(i) com frequência apresenta esquecimento em atividades diárias.

(2) seis (ou mais) dos seguintes sintomas de hiperatividade persistiram por pelo menos 6 meses, em grau mal-adaptativo e inconsistente com o nivel de desenvolvimento:

\section{Hiperatividade:}

(a) frequentemente agita as mãos ou os pés ou se remexe na cadeira;

(b) frequentemente abandona sua cadeira em sala de aula ou outras situaçôes nas quais se espera que permaneça sentado;

(c) frequentemente corre ou escala em demasia, em situações nas quais isto é inapropriado (em adolescentes e adultos, pode estar limitado a sensações subjetivas de inquietação);

(d) com frequência tem dificuldade para brincar ou se envolver silenciosamente em atividades de lazer;

(e) está frequentemente "a mil" ou muitas vezes age como se estivesse "a todo vapor";

(f) frequentemente fala em demasia.

\section{Impulsividade:}

(g) frequentemente dá respostas precipitadas antes de as perguntas terem sido completadas;

(h) com frequência tem dificuldade para aguardar sua vez;

(i) frequentemente interrompe ou se mete em assuntos de outros (por ex., intromete-se em conversas ou brincadeiras). 
B. Alguns sintomas de hiperatividade-impulsividade ou desatenção que causaram prejuízo estavam presentes antes dos 7 anos de idade.

C. Algum prejuízo causado pelos sintomas está presente em dois ou mais contextos (por ex., na escola [ou trabalho] e em casa).

D. Deve haver claras evidências de prejuízo clinicamente significativo no funcionamento social, acadêmico ou ocupacional.

E. Os sintomas não ocorrem exclusivamente durante o curso de um Transtorno Invasivo do Desenvolvimento, Esquizofrenia ou outro Transtorno Psicótico e não são melhor explicados por outro transtorno mental (por ex., Transtorno do Humor, Transtorno de Ansiedade, Transtorno Dissociativo ou um Transtorno da Personalidade).

A partir do DSM-III, os quadros psicopatológicos passaram a ser apresentados como transtornos mentais que podem ser diagnosticados a partir da presença de certo número de sintomas, que devem estar presentes por um determinado tempo (GUARIDO, 2007). Para o diagnóstico do TDAH, o principal sintoma da doença é a falta de atenção. Para alguns professores e algumas mães, todos têm falta de atenção, é uma característica inata do ser humano, não prestar atenção ao que não está agradando, podendo não ser sinal de nenhuma doença.

Transtorno de déficit de atenção com hiperatividade, como eu te disse antes, eu acho que déficit de atenção eu tenho, tu tens, todo mundo tem, dá até para conjugar o verbo aqui. Eu acho que todo mundo é um pouco desatento, sabe. Eu não sei, às vezes eu acho que isso aí já estão tão impregnado que parece que todo mundo tem déficit de atenção. (professor 5).

Para muitas mães e professores o diagnóstico é um alívio, pois se passa a entender o porquê das atitudes da criança. Além disso, tanto para as mães entrevistadas quanto para Uribe e Rojas (2007), o diagnóstico modificou algumas coisas na sua vida: a criança deixou de ser vista como malvada ou malandra, para ser considerada doente; foram tomadas novas medidas educativas, tanto em casa quanto na escola, em razão de sua situação médica.

Segundo Hacking (2006), o mesmo aconteceu com o surgimento do diagnóstico de autismo. Antes, as crianças com características autistas eram afastadas da sociedade e julgadas estúpidas e fracas de espírito. Elas eram consideradas más, mesmo que não tivessem culpa disso. Depois do surgimento desse diagnóstico, elas foram liberadas e outras explicações foram dadas para os seus comportamentos. 
Algumas mães relataram não saber o que significa déficit de atenção, só ficaram conhecendo após o diagnóstico, geralmente por meio de leituras recomendadas pelo médico. $\mathrm{O}$ medo de que seu filho tenha algum tipo de doença mais séria também esteve presente, medo de que ele fosse "deficiente mental", o que tornaria sua aprendizagem mais complicada.

Eu não entendi [o que era TDAH], eu não sabia o que era isso. Sabe o que eu achei que era? Uma criança deficiente, eu achei que era uma criança deficiente. (mãe 3)

A diferença entre TDAH e uma doença também apareceu nas falas dos entrevistados. Nas entrevistas, percebeu-se a presença tanto da dúvida sobre se o quadro é uma doença ou não, quanto a não-aceitação do diagnóstico. A justificativa dada foi que o TDAH é contornável, enquanto as doenças são, muitas vezes, incuráveis.

Há alguns anos, não existia um diagnóstico clínico para as crianças que apresentavam as características do TDAH. Essas crianças sempre existiram, porém elas tinham outros nomes, como exemplifica a frase de uma professora:

Ela [a criança mais agitada] tinha outro rótulo, né? Ela era malcriada, ela era sem-vergonha. Daí o que aconteciam eram punições, "vai lá na diretora, vai”. (professor 4)

A principal causa do TDAH apontada pelos entrevistados foi a genética. Na visão dos entrevistados, o TDAH está relacionado aos pais, a pelo menos um deles. Outras causas também comumente relacionadas ao TDAH pelas mães e professores são o trauma, quando a criança sofre violência em casa, por exemplo, e dificuldades durante a gestação (URIBE; ROJAS, 2007). Alguns professores afirmam conseguir identificar qual dos pais também possui TDAH através de seu encontro com eles.

Engraçado que sempre tem alguém [com o problema na família], o pai ou a mãe. Daí eles chamam a mãe [...], depois vem o pai, aí você percebe certinho quem é, né? Qual dos dois, porque é genético, né? Isso já é comprovado, a grande maioria é genética, até inclusive em crianças adotadas, o pai e a mãe são uma calmaria, e a criança vem [agitada], é genético. (professor 3)

A etiologia é definida como o ramo da medicina que se preocupa com as causas ou origens de uma doença. Para o clínico, é importante conhecer a causa de determinada patologia, pois o tratamento mais eficaz de uma enfermidade em geral se baseia no conhecimento de suas causas. Além disso, o conhecimento das causas ajuda na prevenção das doenças (HACKING, 2000). A busca pela causa do 
1172 TDAH continua, ainda não foi encontrada uma definitiva, mas se cogitam causas genéticas, nutricionais, desequilíbrio de neurotransmissores, dentre outras.

Pelo fato de que as crianças dependem dos adultos para grande parte de suas atividades e necessidades, elas são candidatas à ramificação social do diagnóstico do TDAH. Através dos olhares de seus professores, médicos e pais, o mundo da criança com TDAH requer regulação para administrar sua doença (RAFALOVICH, 2001b). Eles devem cuidar para que ela receba o tratamento adequado à sua classificação e possa se normalizar.

O diagnóstico do TDAH é uma classificação, uma vez que ela nomeia um indivíduo, uma criança, atribuindo-lhe certo número de características que até então não se tinha percebido que ela apresentava. Esse diagnóstico é feito por meio de um conjunto de sintomas que são lidos, traduzidos e interpretados pelo profissional médico. Dar um nome a uma criança, classificá-la, gera uma mudança em sua vida, como será visto na próxima seção.

\section{Os indivíduos}

Hacking (2006) afirma que os indivíduos classificados interagem com sua classificação e esta pode se modificar em razão dessa interação. Isso configura o que Hacking chama de efeito de arco. O efeito de arco é, na verdade, um ciclo entre os indivíduos que são considerados membros da classe e a própria classe. A partir do momento em que o indivíduo tem consciência de sua classificação, ele se modifica, exacerba ou ameniza as características associadas às pessoas dessa classe (efeito feedback positivo ou negativo, respectivamente), o que pode modificar também as características da própria classe.

Seria de se pensar que o efeito de arco só ocorresse em pessoas que possuem consciência de sua classificação. Então, esse efeito não seria possível em crianças com TDAH, pelo menos as menores. Para Hacking (2006), entretanto, podem ocorrer efeitos de arco que englobam unidades sociais mais amplas, como a família e também os professores, no caso específico do TDAH. Ao saber do diagnóstico, a família, principalmente a mãe, assim como os professores, modificam suas atitudes para com a criança, fazendo com que ela também modifique seus comportamentos e a percepção de si mesma, e assim por diante.

Sugere-se que, de maneira geral, o indivíduo com TDAH apresenta um efeito de arco com feedback positivo, pois a criança, ou a família, aceita e reforça as 
características pelas quais foi feito o diagnóstico, que devem então ser tratadas

para que o indivíduo e seu meio voltem à normalidade. A criança, muitas vezes, passa a justificar suas atitudes em razão de sua situação ou a ver características em si mesma que antes ela não identificava, mesmo sem compreender o problema, como demonstra a fala de um professor entrevistado:

[...] a gente escuta às vezes assim "mas é que eu tenho problemas, eu tenho problemas", eles dizem. (professor 2)

Segundo os entrevistados, geralmente a criança não sabe o que está acontecendo, não sabe que tem TDAH. Quando a mãe conta, é por alguma razão específica, algum acontecimento. As crianças que tomam Ritalina ${ }^{\circledR}$ o fazem sem saber o motivo, ou então este é mascarado, afirmando à criança que ela precisa tomar o medicamento para aprender, ou para ficar mais atento, nunca dizendo que ele tem algum problema específico.

Ele toma remédio, mas eu penso [...] que ele não sabe "eu tenho um transtorno, um déficit, hiperatividade". (professor 3)

Já as crianças maiores entendem um pouco mais, apesar de não compreenderem muito bem o que significa TDAH. Os esforços são sempre no sentido de amenizar as situações, fazer com que a criança sofra o menos possível, ou então que ela seja alheia à classificação que lhe é imposta. A fala abaixo exemplifica como uma mãe contou para o seu filho que ele tem TDAH, sempre ressaltando os pontos positivos e tentando proteger a criança.

Então eu cheguei em casa e falei pra ele [...] Picasso tinha, o gênio da matemática tinha, Tom Cruise tem, sabe, tem vários gênios que têm o DDA [déficit de atenção], não é só ele. Os dois, o Picasso e o Pablo, [...] eles também tinham DDA e de uma hora pra outra, eles se tornaram gênios. Aí eu falei pra ele "não fica pensando que você é uma pessoa excluída" [...]. (mãe 4)

A família, e muitas vezes também a escola, pretendem constituir uma cápsula protetora para a criança com TDAH. Dentro desta cápsula, a criança pode ser cuidadosamente protegida pelo controle de informação (GOFFMAN, 2008). Ou seja, as informaçôes são "filtradas" antes de serem repassadas às crianças.

Apesar dessa proteção, a criança ainda sente a resposta gerada por sua classificação. E maior é esse sentimento quanto maior for a criança. Já foi dito anteriormente que os professores e a família mudam com a criança após o diagnóstico. Seria estranho pensar que ela não fosse notar tal diferença. 
Algumas crianças maiores, entretanto, não gostam de ser diferentes e não aceitam ser tratadas de maneira diferente.

Claro, não dá pra deixar ele o tempo inteiro não fazendo [as mesmas coisas que as outras crianças fazem], porque ele vai querer também. Eles percebem isso, o [aluno com TDAH] da sétima série não admite, [...], ele quer fazer igual a todo mundo [...]. (professor 3)

O indivíduo estigmatizado possui as mesmas concepções de normalidade do indivíduo que é considerado normal (GOFFMAN, 2008). Portanto, os indivíduos que possuem consciência de sua classificação querem ser tratados da mesma maneira que os demais, talvez até por não se considerarem doentes ou por não acharem que apresentam as características daquela classe.

Ao mesmo tempo em que têm intenção de proteger os filhos, cuidar para que não sofram, as mães relataram que eles precisam de um acompanhamento especial, diferenciado, por parte da escola, ponto de vista também encontrado nas entrevistas com os professores. Segundo eles, para aprender, a criança com TDAH precisa ter uma atenção diferenciada, e geralmente essa atenção é recomendada pelo profissional da saúde.

A dificuldade em aprender, derivada da falta de atenção, principal característica do TDAH, faz com que as crianças tirem notas inferiores às dos seus colegas, uma grande preocupação relatada pelas mães. Uma delas descreve a escola como um lugar ruim para seu filho, onde ele é vítima de chacotas e preconceitos.

Porque ele indo na escola, a criança passa a ser chacota, porque [...] chega o dia do boletim, é uma coisa ridícula o que eles fazem: "quem tirou acima 7 [em todas as matérias] vai receber [o boletim], quem não tirou, a mãe vai vir [buscar na escola, diretamente com o professor]. Gente, isso é uma humilhação, não pode acontecer isso na escola, de jeito nenhum, ou todo mundo recebe, ou ninguém recebe. Isso é uma discriminação, não pode acontecer, porque se o meu filho está aqui, o colega do lado dele tirou 10, a professora passa, dá pra ele [o boletim] e não dá pro meu filho. Ele está sendo humilhado, eles não veem esse lado? (mãe 4)

A criança é reconhecida como sendo diferente das demais, segundo Goffman (2008), através dos símbolos de estigma. Esses símbolos consistem nas informações sociais repassadas pelo indivíduo estigmatizado através de sinais ou signos específicos que despertam a atenção dos que estão ao redor. Eles podem ser físicos, como uma cicatriz ou defeito visível no corpo, ou comportamentais, como a hiperatividade, no caso do TDAH. 
Durante as entrevistas realizadas, foi relatado por praticamente todos os entrevistados que, quando a criança está realizando alguma atividade que lhe agrada, ela deixa de ser desatenta e agitada. Dessa forma, nessa situação, quem não sabe sobre o diagnóstico não imagina que ela tem algum problema, ou melhor, ela não está repassando os signos da sua doença. Isso tem a ver também com a visibilidade do estigma, ou seja, até que ponto o indivíduo comunica ao outro seu problema (GOFFMAN, 2008). Nos casos relatados, a escola é o principal local onde aparecem os símbolos do estigma, onde eles apresentam maior visibilidade, pois é lá que a falta de atenção aparece e, consequentemente, a dificuldade de aprendizagem.

Quando se vai da família para a rede social mais ampla, como a comunidade ou mesmo a escola, pode-se dizer que existem dois tipos de indivíduos, os que conhecem a classificação da criança e os que não conhecem. Os conhecedores da situação, por um lado, reagem à classificação de formas diferentes. Segundo as mães e os professores, existem os que, por saberem do diagnóstico, mudam suas atitudes de forma a ajudar a criança; e existem os que reagem através do preconceito contra aquela criança, como descreve a fala de um professor:

Eu vejo assim: que uma criança que tem um problema mais sério, ela é, na verdade, um pouco excluída pelo grupo. (professor 1)

Às vezes, os pais dos colegas de escola da criança não gostam da ideia de terem na sala uma criança tão agitada, diferente das demais, com um diagnóstico médico, como exemplifica a fala de outro professor. Para eles, uma criança com algum problema atrapalha a vida em sala de aula: como o professor dá mais atenção à criança problemática, seu filho acaba sendo o prejudicado.

Tem um pai que me disse assim: "ah, vocês estão incluindo, falando da inclusão, vocês estão incluindo o aluno com deficiência, déficit ou transtorno e excluindo os outros que aprendem". (professor 3)

Os que não conhecem a classificação de determinada criança, por outro lado, tendem a achar, segundo as mães, que seus filhos são preguiçosos e mal-educados. De modo geral, as mães e os professores ainda acham melhor que a criança seja rotulada de doente do que de preguiçoso, pois pelo menos suas atitudes não são devidas a ela mesma, mas sim ao problema que possui; ela não tem culpa ou responsabilidade sobre suas atitudes. Juntamente com a medicalização dos desvios, tem ocorrido também uma mudança na responsabilidade atribuída desses desvios: 
com maldade (ou mesmo com a falta de educação), os desviantes são considerados responsáveis por seus comportamentos; com a doença eles não o são, ou pelo menos a responsabilidade é diminuída (CONRAD; SCHNEIDER, 1992).

Collares e Moysés (1996) afirmam que localizar o problema na criança significa perpetuar a situação, culpabilizando a vítima. Além disso, essa atitude leva à estigmatização das crianças, até então consideradas sadias, que incorporam esse rótulo, direta ou indiretamente, ${ }^{4}$ se sentem doentes e agem como tal, tornando-se doentes. Aí sim, suas chances de aprender ou de mudar são reduzidas, por causa do efeito de arco assim gerado.

\section{Os informados}

Erwin Goffman (2008) descreve um conjunto de indivíduos dos quais a pessoa classificada ou, em suas palavras, estigmatizada, pode esperar algum apoio, que são os informados. Um tipo de informado é aquele indivíduo que se relaciona com o classificado através da estrutura social. Segundo Goffman (2008), trata-se de uma relação na qual a sociedade mais ampla acaba considerado ambos como uma só pessoa, caso em que se encontram as mães das crianças diagnosticadas com TDAH.

As mães relatadas revelaram que são as principais responsáveis pelo cuidado com o filho "problemático" e algumas delas afirmaram que deixaram de trabalhar e cuidar de seus afazeres para se dedicarem inteiramente àquele filho.

Eu tive que anular a minha vida para viver a dele, porque eu vivo em função do Lucas, eu vivo em função dele, eu me dedico inteiramente a ele. (mãe 3)

Para alguns autores, o TDAH altera drasticamente e vida familiar. As famílias com crianças com TDAH têm experiências em sua vida cotidiana inimagináveis para famílias que não enfrentam esse tipo de problema: há mais tensão e discussão, o barulho é constante, a hora do jantar pode ser perturbadora e comer fora pode se tornar um desafio (PHELAN, 2005), dentre outras dificuldades, situação que também foi descrita por algumas das mães entrevistadas.

Os informados vivem como se também fossem classificados. No caso do TDAH, muitas vezes as crianças classificadas são pequenas e não entendem diretamente o que está acontecendo. Nesses casos, sugere-se que as mães sofram mais pressão da sociedade por seu filho não ser normal do que a própria criança, ou seja, são mais estigmatizadas que os estigmatizados. 
Esse vizinho aqui do lado falou na minha cara "leva esse menino pra algum lugar, esse menino não é bem certo". [...] Eu fiquei tão sentida, eu chorei tanto, eu disse: "meu Deus do Céu, se ele tiver que pagar com a própria língua o que ele falou do meu filho". (mãe 3)

Para Phelan (2005), a primeira pessoa que sente as consequências do TDAH não é a criança, mas a mãe. Pelas entrevistas realizadas, foi possível perceber que muitas delas sofrem com os comportamentos do filho e acabam também ganhando um diagnóstico, o de depressão.

É difícil, eu entrei em depressão grave. Eu já entrei duas vezes, saí, porque assim, você não tem ajuda, você vê que o seu filho está passando por isso, ele não vai sair disso [...]. (mãe 4)

As mães podem ser consideradas as principais sofredoras com o transtorno de seus filhos e a vida em suas casas, muitas vezes, é um caos. Mesmo assim, elas se consideram as principais responsáveis pela educação de seus filhos. São elas que devem cuidar para que eles sejam aceitos por todos como crianças normais e de bem (URIBE; ROJAS, 2007).

$\mathrm{O}$ acesso à informação, entretanto, para as mães, torna a aceitação do diagnóstico mais fácil. Ler e entender sobre o problema, segundo elas, faz com que consigam lidar melhor com a situação. Para as que já conheciam o problema, o diagnóstico de TDAH não foi um choque, pois já identificavam ou viam características no filho que indicavam o transtorno.

Não teve, vamos dizer, impacto nenhum [o diagnóstico], porque pelo que a gente escutava na televisão e reparava nele [no filho], a gente já tinha uma ideia do que seria. (mãe 2)

A responsabilidade sobre os cuidados com a criança recai sobre a mãe, já que o pai, muitas vezes, é bastante ausente na vida do filho, seja por trabalhar, para possibilitar que a mãe possa ficar com a criança, seja por não compartilhar da opinião de que o filho possui algum tipo de problema. Além disso, essas famílias não recebem apoio de algum núcleo social mais amplo, como a vizinhança ou então a família ampliada (avós, tios). Esse pode ser um dos motivos pelos quais a mãe acaba se tornando a pessoa que mais sofre com os problemas do filho.

Para os professores, o diagnóstico representa para a família uma preocupação, já que eles não sabem como lidar com o problema. Geralmente, eles aceitam sugestôes da escola e do médico sobre como lidar com o filho em casa. Ao mesmo tempo, segundo os professores, deve ser melhor para os pais terem o filho 
diagnosticado com TDAH, situação que explica o comportamento do filho, do que um filho que incomoda na escola sem esse diagnóstico. Neste último caso, eles recebem muita reclamação da escola em relação ao seu filho, como descreve um dos professores entrevistados:

Eu acho que se [...] a gente tem um aluno que incomoda muito e cada vez que ele [o pai ou a mãe] vem [conversar] você vai reclamar, [...] como professora eu estou falando, eu acho que os pais não gostam, $[. .$.$] porque na verdade [. .$.$] talvez eles nunca$ recebam um elogio do filho, só as coisas negativas. (professor 1)

É possível perceber que os informados, no sentido de Goffman (2008), também são afetados com uma classificação, um estigma. Sugere-se, portanto, que a unidade que sofre o efeito de arco, no caso específico do TDAH, não é somente a criança, e sim o núcleo formado por ela e pelos informados mais próximos (pais e professores principalmente).

\section{As instituiçôes}

Todo diagnóstico médico é uma classificação, para a qual existem características definidas, e na qual alguns indivíduos com essas características se enquadram. Mas para que um diagnóstico, uma classificação, seja levada em consideração, entre na sociedade, é necessário que haja algo que a legitime, precisa haver uma instituição que a torne verdadeira, que a utilize (HACKING, 2007). Além disso, é a partir das instituições que se garantem as normas (LECOURT, 2006).

No caso do TDAH, existem as clínicas médicas ou multiprofissionais onde são feitos os diagnósticos. Além disso, pode-se dizer também que o DSM é uma forma de instituição que apresenta uma série de características de comportamento, que posteriormente é interpretada por um especialista da área.

A primeira versão do DSM data de 1952, e até 1980, quando foi publicado o DSM-III, os fundamentos diagnósticos encontrados nesses manuais apresentavam influências da psicanálise e da psiquiatria social comunitária. A versão do DSM-III rompe com a psiquiatria clássica e, a partir de então, os quadros psicopatológicos passaram a ser apresentados como transtornos mentais. Esses transtornos são diagnosticados a partir da presença de certo número de sintomas (identificados por meio de uma lista) que devem estar presentes na vida do indivíduo por determinado período de tempo. Atualmente, o DSM-IV revisado é uma referência mundial de diagnósticos dos transtornos mentais (GUARIDO, 2007). 
O que se sugere aqui é que a escola também é uma instituição de legitimação do diagnóstico de TDAH. Ela apresenta os alunos problemáticos ao profissional de saúde e os recebe de volta com o diagnóstico, aceitando-o e reproduzindo o seu discurso. Então, se a escola encaminha, aceita o diagnóstico e até modifica suas atitudes em função dele, ela pode ser considerada uma instituição de legitimação desse diagnóstico.

Ao assumir e validar os discursos médico-psicológicos, a pedagogia mantém essa prática, desresponsabilizando a escola. $\mathrm{O}$ discurso médico que aparece na escola é o mesmo discurso difundido na mídia leiga. Dessa forma, é relativamente comum que professores e coordenadores façam diagnósticos por meio da observação de determinados comportamentos das crianças, e as encaminhem para avaliação psicológica (GUARIDO, 2007). As mães e os professores relataram que, na grande maioria dos casos, realmente é a escola quem solicita aos pais para encaminharem seus filhos ao profissional de saúde.

A principal causa [para o encaminhamento da criança ao profissional da saúde] foi a escola, porque [...] todo dia tinha alguma coisa: é o Lucas isso, o Lucas aquilo; a professora Marina “o Lucas fez isso, o Lucas fez aquilo". (mãe 3)

Muitas crianças podem incorporar a incapacidade, a doença, considerandose pouco inteligentes. Assim, elas são expropriadas de sua normalidade. Elas são normais, mas com o passar do tempo, vão se tornando doentes. E só mostram que aprendem quando conquistam sua confiança, o que não acontece na escola, pois é lá que disseram que elas não sabem (COLLARES; MOYSÉS, 1996). É o caso das crianças que sempre precisam que o pai ou mãe vá buscar o boletim com suas notas. 5 Para algumas mães entrevistadas, esse tipo de atitude faz com que ele se sinta diferente dos outros e o torne mais consciente de seu problema.

Dessa forma, segundo Legnani e Almeida (2004), a escola demanda dos educadores uma postura baseada na caridade. Dessa forma, o aluno encaminhado parece estar numa posição de inferioridade em relação aos colegas. Sua diferença é sempre reafirmada, ele não é visto como um igual, conforme relatam um professor e uma mãe:

Ele percebe sim que é diferente, [...] ele se sente diferente dos outros. (professor 4)

Ela [a professora] não pode comparar as outras crianças com o Lucas, porque o Lucas não é igual a essas outras crianças que estão junto com ele lá. O Lucas não é igual, o Lucas é hiperativo, elas [as crianças que não têm TDAH] conseguem se concentrar. (mãe 3) 
A escola é um lugar de homogeneização de comportamentos, não dando muito espaço aos diferentes. Em relação ao TDAH, uma mãe se mostrou descontente com essa característica e afirma que o lado bom de seu filho ninguém vê na escola, só seus defeitos:

[...] eles não sabem aproveitar o lado que o Douglas mostra interesse, e acredito que isso passe pelos outros também. (mãe 4)

Além disso, o tratamento médico, em geral, é reavaliado baseando-se no relatório dos professores da criança. Portanto, é a partir desse relatório que se decide se a criança precisa tomar medicamento, ir a um psicólogo, se está melhor, se piorou, se nada mudou.

[A médica] sempre pede "você traz um relatório total da escola". Através desse relatório, ela vai ver o que ela pode e o que não pode fazer pelo Lucas, se ele está melhorando, se ele está piorando, se ela tem que mudar alguma coisa do remédio, alguma outra coisa também. (mãe 3)

É a partir das instituições que as crianças recebem uma classificação e também é a partir delas que essa classificação é legitimada. No caso do TDAH, é por meio do DSM que o médico faz o diagnóstico do problema, comparando os comportamentos descritos pela escola e pelos pais da criança com uma lista de sintomas do TDAH (quadro 1). A escola desempenha u papel fundamental nesse processo, tanto na identificação (através dos encaminhamentos aos profissionais de saúde) quanto no reconhecimento e na validação do problema. Isso porque, após o diagnóstico, a criança volta para a escola e lá é recebida de uma maneira diferente, como alguém que precisa de ajuda e que não tem culpa por seus comportamentos; após o diagnóstico, muitas vezes a escola até modifica algumas de suas regras e normativas para que essa criança "doente" possa se inserir no ambiente escolar.

\section{O conhecimento e os especialistas}

Por trás de uma classificação, existe um corpo de conhecimento sobre o tipo de pessoas em questão, ${ }^{6}$ as características que apresenta e que estão relacionadas a essa classificação. E parte desse conhecimento é precisamente detalhado e conhecido pelos especialistas da área (HACKING, 2007), que escrevem livros sobre o assunto, criam guias para outros especialistas fazerem o diagnóstico e também fazem o diagnóstico. 
Os especialistas utilizam o poder do discurso científico para impor aos demais o que consideram que seja a verdade. No Ocidente, dizer que algo é científico equivale a dizer que ele é verdadeiro. Os meios de comunicação em massa passam a mensagem de que a ciência é quase mágica e os cientistas são considerados uma autoridade (CAMARGO JR, 2003). Na sociedade moderna, tem havido um crescimento substancial no prestígio, domínio e jurisdição da profissão médica (CONRAD; SCHNEIDER, 1992).

Com o aparente sucesso da medicina no controle de doenças contagiosas, o crescimento da biomedicina científica, a regulação da educação médica e licenciamento, e sua organização política e lobbying da Associação Médica Americana, o prestígio da profissão médica aumentou. A área da saúde, em especial a profissão médica, domina a organização do cuidado em saúde e tem praticamente um monopólio de tudo o que é definido como tratamento médico, especialmente em termos do que constitui uma doença e qual é a intervenção médica apropriada (CONRAD; SCHNEIDER, 1992).

A gente ficou meio assim [desconfiado] com a questão do remédio, [...] mas se o médico que é médico diz que é bom e que não faz mal, o que a gente vai dizer? Não temos conhecimento. (mãe 2)

A influência deles é vista tanto na casa das crianças com TDAH quanto na escola. As atitudes da família e dos professores mudam, de acordo com as orientações dos profissionais da saúde. Nossa sociedade busca a eficiência a todo custo, é uma sociedade das urgências, essencialmente hiperativa, que se utiliza de rótulos científicos como métodos de controle da subjetividade (FIORE, 2005).

Em relação ao TDAH, o discurso médico é responsável pela diferenciação de certos tipos de crianças, pois é por meio de rótulos, ou diagnósticos, que se definem o que é atenção, quais habilidades se deve ter em cada idade, como é ser inteligente. "A busca pelo alcance desses padrões se torna a 'grande' função da ciência” (FIORE, 2005, p. 372). As mães demonstraram grande preocupação com o futuro de seus filhos, as crianças que não apresentam as habilidades consideradas normais para suas faixas etárias.

$[T]$ emos que fazer alguma coisa, não dá mais assim, [...] o que vai ser desse menino [se ele continuar assim]? (mãe 3 )

A prescrição de rótulos científicos é uma eficiente estratégia de controle subjetivo (FIORE, 2005). A tendência é a reprodução de um discurso que 
pode se tornar padronizante e inquestionável, uma vez que o discurso deriva do meio científico, e a ciência ocupa, no Ocidente, o lugar de maior produtora de verdades (TESSER, 2007). Os conhecimentos médicos, assim, são considerados verdades do ponto de vista operacional. O profissional considera que está fazendo o melhor ao encontrar um diagnóstico e prescrever um tratamento baseado nos saberes científicos. Já o doente, geralmente leigo no assunto, recebe com muita confiança a versão médica, normalmente considerando-a uma verdade (TESSER, 2007). Dessa forma, o profissional da saúde é considerado o principal detentor da informação sobre o TDAH.

Se o médico que é médico diz que é bom e que não faz mal, o que a gente vai dizer [...]; não temos conhecimento, né? (mãe 2)

Apesar do poder do discurso científico, grande parte dos professores e pais são resistentes ao uso do medicamento. Muitas vezes os pais o dão às crianças contra sua vontade ou então rejeitam a opinião médica e não seguem o que foi prescrito. Isso demonstra que ainda há certa resistência ao uso de psicotrópicos em crianças pela sociedade.

[...] esses remédios fazem mal, são uma droga, são faixa preta, ele [a criança] é novo ainda. (mãe 3)

Pelo relato das mães e dos professores, foi possível perceber que, se há dúvidas quanto ao problema da criança, se ela é doente ou não, se seus maus comportamentos derivam de "falta de educação" ou de uma patologia, essas são sanadas quando ocorre a consulta médica. Geralmente ela fornece a resposta final ao problema: a criança ou tem TDAH ou não tem. A partir dessa consulta é que as medidas restauradoras são tomadas.

O profissional da saúde e seu conhecimento científico têm o poder de modificar a maneira como a família e a escola veem a criança, e até como ela própria se vê. É a partir do diagnóstico que as atitudes se modificam para com essa criança e pode ocorrer o efeito de arco, como já foi discutido acima.

\section{Considerações finais}

Para Illich (1975), uma sociedade superindustrializada causa doenças, uma vez que os homens não conseguem se adaptar à ela. Para ele, o diagnóstico médico serve para explicar que, se o indivíduo não se adapta à sociedade, não é por 
causa do meio ambiente desumano, mas porque seu organismo está falhando.

"Assim, a doença retira sua própria substância do corpo do homem. O médico a caracteriza e a denomina segundo a intenção do paciente” (p. 154, grifo do autor). A classificação das doenças adotadas por uma sociedade reflete sua estrutura institucional e a origem social das doenças está na necessidade da isenção de culpa das instituiçôes.

A maneira de agir do profissional da saúde tende a ser dominado pela padronização operacional e científica das doenças, que seria um instrumento de intermediação entre o profissional e o doente, buscando a cura ou o controle dessa doença (TESSER, 2007). O DSM-IV representa essa operacionalização, por meio de uma lista de sintomas comportamentais, sobre os quais se baseiam os diagnósticos do TDAH.

Tanto os pais quanto os professores e os profissionais de saúde procuram por explicações e maneiras de lidar com os desafios representados pelos comportamentos infantis considerados anormais. Na sociedade atual, o modelo da medicina científica possui um poder cultural muito grande. Assim, a maior parte da população assume como verdade que, se os médicos falam que certos comportamentos são na realidade uma doença, então essa doença realmente existe (TIMIMI, 2002). Segundo Timimi (2002), a construção do TDAH como uma doença biomédica surgiu como uma resposta ao crescimento das ansiedades culturais sobre o desenvolvimento infantil e seu bem-estar.

Este rótulo diagnóstico dá a impressão de que as crianças que os possuem são similares e minimiza suas diferenças. Uma vez que o TDAH é visto como uma doença, as crianças com dificuldades de aprendizagem ou comportamento, que podem estar sendo causados por uma série de processos complexos, podem agora ter o rótulo de uma doença. Tal rótulo cria a ilusão de que a informação e a compreensão científicas da condição daquela criança já estão disponíveis (TIMIMI, 2002).

Ser classificado, ganhar um nome, é muito comum. Quando este nome, porém, está relacionado a um discurso oficial, como o discurso científico, geralmente reconhecido pela sociedade como uma verdade, ele interage com o classificado de forma mais profunda, duradoura. Isso porque existe uma estrutura subjacente a essa classificação, que engloba a própria classificação, os indivíduos classificados, as instituições, o conhecimento e os especialistas, como discutido anteriormente. 
O TDAH infantil é um diagnóstico e, portanto, uma classificação que possui essa estrutura, que é responsável pela aceitação desse nome e sua permanência na sociedade. O diagnóstico do TDAH é baseado no discurso científico, apresenta uma lista de sintomas que caracterizam o indivíduo TDAH-positivo ou TDAHnegativo. Após a classificação, pode ocorrer o efeito de arco, inclusive no caso de crianças pequenas, pois toda a estrutura social muda em fator do nome que a criança recebeu, mas ele representa também um alívio para as mães e para os professores.

Dessa forma, o diagnóstico de TDAH é dúbio, pois ajuda na resolução imediata do problema da criança na escola, livrando a família da culpa pela nãoaprendizagem e mau comportamento dela. Ao mesmo tempo, entretanto, as consequências de se nomear alguém tão cedo com um diagnóstico de transtorno mental também podem vir a gerar uma resposta na própria criança. Sugere-se que essa resposta seja de afirmação dos sintomas da doença; e a criança, quando mais velha ou até mesmo depois de adulta, se veja como incapaz de realizar as atividades do cotidiano como outra pessoa considerada "normal".

\section{Referências}

ANDRADE, E.R.; SCHEUER, C. Análise da eficácia do metilfenidato usando a versão abreviada do questionário de Conners em transtorno de déficit de atenção/hiperatividade. Arquivos de Neuropsiquiatria, v. 62, n. 1, p. 81-85. 2004.

BARDIN, L. Análise de conteúdo. Lisboa: Ediçōes 70, 1977. 225 p.

CAMARGO JR, K.R. Biomedicina, Saber \& Ciência: uma abordagem crítica. São Paulo: Hucitec, 2003. 195 p.

COLLARES, C.A.L.; MOYSÉS, M.A.A. Preconceitos no cotidiano escolar: ensino e medicalização. São Paulo: Cortez, 1996. 264 p.

CONRAD, P.; SCHNEIDER, J.W. Deviance and medicalization: from badness to sickness. Philapelphia: Temple University Press, 1992. 327 p.

DSM-IV-TR. Manual Diagnóstico e Estatístico de Transtornos Mentais. 4 ed. (rev). Porto Alegre: Artmed, 2002. $880 \mathrm{p}$.

FIORE, M.A. Medicalização do corpo na infância: consideraçôes acerca do Transtorno do Déficit de Atenção e Hiperatividade. Mnemosine, v. 1, n. 1, p. 365-380. 2005.

GOFFMAN, E. Estigma: notas sobre a manipulação da identidade deteriorada. 4. ed. Rio de Janeiro: LTC, 2008. 158 p.

GUARIDO, R. A medicalização do sofrimento psíquico: considerações sobre o discurso psiquiátrico e seus efeitos na educação. Educação e Pesquisa, v. 33, n. 1, p. 151-161. 2007. 
HACKING, I. Múltipla personalidade e as ciências da memória. Rio de Janeiro: José Olympio, 2000.357 p.

. O autismo: o nome, o conhecimento, as instituições, os autistas - e suas interações. In: RUSSO, M.;CAPONI, S. (Org.). Estudos de filosofia e história das ciências biomédicas. São Paulo: Discurso Editorial, 2006. p.305-320.

Kinds of people: moving targets. Proceedings of the British Academy, v. 151, n., p. 285-318. 2007.

ILLICH, I. A expropriação da saúde: nêmesis da medicina. Rio de Janeiro: Nova Fronteira S.A., 1975.196 p.

LECOURT, D. Normas. In: RUSSO, M.; CAPONI, S. (Org.). Estudos de filosofia e história das ciências biomédicas. São Paulo: Discurso Editorial, 2006. p.292-303.

LEGNANI, V.N.; ALMEIDA, S. F. C. A construção da infância: entre os saberes científicos e as práticas sociais. Estilos da Clínica, v. IX, n. 16, p. 102-121. 2004.

PHELAN, T.W. TDA/TDAH: Transtorno de Déficit de Atenção e Hiperatividade. 1. ed. São Paulo: M Books do Brasil., 2005. 246 p.

RAFALOVICH, A. The conceptual history of attention deficit hyperactivity disorder: idiocy, imbecility, encephalitis and the child deviant, 1877-1929. An Interdisciplinary Journal, v. 22, n., p. 93-115. 2001a.

Disciplining domesticity: framing the ADHD parent and child. The Sociological Quarterly, v. 42, n. 3, p. 373-393. 2001b.

TESSER, C.D. A verdade na biomedicina, reações adversas e efeitos colaterais: uma reflexão introdutória. Physis: Revista de Saúde Coletiva, v. 17, n. 3, p. 465-484. 2007.

TIMIMI, S. Pathological child psychiatry and the medicalization of childhood. New York: Brunner-Routledge, 2002. 190 p.

URIBE, C.A.; ROJAS, R.V. Factores culturales en el trastorno por déficit de atención e hiperactividad: habla la mamá. Revista Colombiana de Psiquiatria, v. XXXVI, n. 2, p. 255-291. 2007.

VASCONCELOS, M.M. et al. Prevalência do transtorno de déficit de atenção/hiperatividade numa escola pública primária. Arquivos de Neuropsiquiatria, v. 61, n. 1, p. 67-73. 2003.

\section{Notas}

${ }^{1}$ Este trabalho foi resultado parcial de dissertação de mestrado defendida no Programa de Pós-Graduação em Saúde Pública da Universidade Federal de Santa Catarina. Foi aprovado pelo Comitê de Ética em Pesquisa com Seres Humanos da mesma universidade, sob o parecer no 180/2008. A pesquisa recebeu apoio do CNPq e da CAPES.

${ }^{2}$ Do inglês looping effect. 
${ }^{3}$ Sigla em inglês para o Manual Diagnóstico e Estatístico dos Distúrbios Mentais, terceira edição.

${ }^{4}$ Diretamente, quando a criança é capaz de entender o nome que lhe foi dado, mudando suas atitudes de uma forma direta. E indiretamente, quando ela é pequena demais para captar o significado de sua classificação; nessa situação, a família e a escola, por exemplo, mudam suas atitudes para com ela, o que acaba por modificar também suas atitudes.

${ }^{5}$ É comum, nas escolas onde as entrevistas ocorreram, que as crianças que tirem alguma nota inferior a 7,0 no boletim, os pais compareçam à escola para retirá-lo. Segundo as escolas, esse método é necessário para que esses pais conheçam a realidade quantificável do filho na escola, para que ele tenha consciência do "rendimento" de seu filho. Para os "bons alunos", os boletins são entregue dentro da sala de aula, perante todos os colegas.

${ }^{6}$ Fala-se aqui tanto do conhecimento de especialistas quanto do conhecimento popular. 


\section{Attention-Deficit Hyperactivity Disorder: Classification and Classified}

The main object of this paper is to analyze the views of parents and teachers on the Attention-Deficit Hyperactivity Disorder (ADHD) and its effect on diagnosed children. Mothers and teachers of ADHDdiagnosed children were interviewed following a semistructured interview outline. This paper examines a thematic axis that arose from the interviews, namely classification and classified. The structure of a classification, according to Ian Hacking, involves five main aspects: the classification itself, the classified individuals, the institutions, the knowledge, and the specialists. This author claims that every classification of people gives rise to a response, that is, the classification and the individual being classified interact, forming a cycle that Hacking called the looping effect. ADHD is a medical diagnosis, and thus, a classification. ADHDdiagnosed children correspond to the individuals being classified. We intend to show that even small children, who do not understand the meaning of the classification given to them, can possibly be subjects to the looping effect. The child, through modifications in her social surroundings, modifies herself, realizing that she is different. The institutions are responsible for the legitimating of diagnosis and in the case of ADHD, they correspond not only to health facilities, but also to schools. Besides that, behind each classification there is also a body of knowledge about it, and part of this knowledge is dominated by specialists.

Key words: Classification of People, ADHD, Looping Effect. 